\title{
Effect of Passive Smoking on the Lung of Young Lambs
}

\author{
ARLENE STECENKO, KENNETH MCNICOL, AND RUSSELL SAUDER \\ Division of Pulmonary Disease/Cystic Fibrosis, Department of Pediatrics, University of Florida, College of \\ Medicine, Gainesville, Florida 32610
}

\begin{abstract}
The effect of passive smoking on lung histology, lung mechanics, and airway responsiveness (AR) was studied in 2-month-old lambs. Two groups of lambs were studied; 17 were exposed to cigarette smoke (CS) and 13 served as age- and sex-matched controls. Starting at 1 month of age, CS lambs had 25 daily exposures to the smoke generated from eight cigarettes. A smoking machine was constructed for the study using a Bird Ventilator. Two days prior to lung function testing, lambs were anesthetized and a Silastic balloon was placed in the pleural space for later measurement of pleural pressure. At the beginning of each study, lambs were intubated with a nasotracheal tube over a flexible fiberoptic bronchoscope. Lung mechanics (dynamic compliance, resistance of the lung, functional residual capacity) and $A R$ were measured using a whole body plethsymograph. AR to inhaled histamine, carbachol, and citric acid was measured in each lamb on 3 separate days by giving five breaths of increasing concentrations of the aerosol in a noncumulative fashion. AR was measured both within $24 \mathrm{~h}$ of the final exposure to $\mathrm{CS}$ and at 3-7 days after CS. After the final AR was measured, lambs were anesthetized and an open lung biopsy performed. Control lambs had the same studies as CS lambs performed at an equivalent age. After 25 daily exposures to CS in 17 lambs, mean dynamic compliance was $0.024 \pm 0.009$ liter/ $\mathrm{cm} \mathrm{H}_{2} \mathrm{O}$, lung resistance was $2.56 \pm 1.32 \mathrm{~cm} \mathrm{H}_{2} \mathrm{O} \cdot$ liter $^{-1}$. $\mathrm{s}$, and functional residual capacity was $0.725 \pm 0.234$ liter. These values were not significantly different $(p>0.05)$ from those of the control lambs. Exposure to CS did not significantly change AR to any of the three bronchoprovocation agents tested. Histologic examination of lung tissue showed mild to moderate interstitial mononuclear cellular infiltrate, cellular debris in some airways, and occasional peribronchial inflammation in CS lambs but not in controls. Thus, passive smoking for 1 month in young lambs was not associated with a detectable alteration in lung mechanics or airway responsiveness at a time when inflammatory cells were found in the lung. (Pediatr Res 20: 853-858, 1986)
\end{abstract}

\section{Abbreviations}

$\mathrm{CS}$, cigarette smoke

$\mathrm{COHb}$, carboxyhemoglobin

FRC, functional residual capacity

BTPS, body temperature, pressure, saturation

$V_{\mathrm{T}}$, tidal volume

V, flow

$\mathbf{P}_{\mathrm{a} o}$, airway opening pressure

Received September 30, 1985; accepted April 25, 1986.

Address for correspondence and reprints Arlene A. Stecenko, Pediatric Pulmonary Center, Box J-296, JHMHC, Gainesville, FL 32610.

Supported by NIH Grant HL 30928-02, American Lung Association of Florida.

\author{
$\mathbf{P}_{\mathrm{pl}}$, pleural pressure \\ $\mathbf{P}_{\mathrm{tp}}$, transpulmonary pressure \\ Cdyn, dynamic compliance \\ $R_{L}$, resistance of the lung \\ $R R$, respiratory rate \\ $\mathrm{S}_{\mathrm{GL}}$, specific conductance \\ $\mathrm{S}_{\mathrm{Cdyn}}$, specific compliance \\ AR, airway responsiveness
}

It has long been recognized that cigarette smoking is associated with significant pulmonary disease. More recently, the potential harm of "breathing other people's smoke" (1), i.e. passive smoking, has been examined. Epidemiologic data from the United Kingdom (2), New Zealand $(3,4)$, and the United States (5) suggest that children whose mothers smoke cigarettes have a higher incidence of bronchitis, pneumonia, wheeze, and hospital admissions for respiratory disease compared to children whose mothers do not smoke. Tager et al. (6) recently showed a disturbing decrease in lung growth, as assessed by the yearly increase in the 1-s forced expired volume, in school children whose mothers smoked cigarettes. Similarly, spouses of smokers have significantly decreased pulmonary function as measured by spirometry when compared to spouses of nonsmokers (7). Thus, passive smoking may be harmful to the lungs, particularly the airways.

Long-term active smoking of cigarettes certainly contributes to the development of chronic airways disease. The acute effects of smoking on airway function have been examined: basically there is an increase in airway resistance and diminished flows over the midportion of the forced vital capacity after inhaling a cigarette (8). Long-term cigarette smokers who are asymptomatic and whose pulmonary functions are normal by routine measurements, may show abnormalities using more sensitive tests. These abnormalities may include increased airway reactivity to inhaled methacholine or histamine (9-12).

Since school children whose mothers smoke have an increased incidence of cough and wheeze, and since asymptomatic smokers have increased airway responsiveness to aerosol challenge, an early sign of lung damage resulting from exposure to CS may be airway hyperreactivity. This is a difficult hypothesis to test in the human. For this reason, exposure of different species of animals to CS has been used to assess the effect of smoking on airway function. Roehrs et al. (13) were unable to show an increased airway reactivity to aerosolized methacholine in adult baboons who actively smoked for 6 pack-yr. However, it may be that the early damaging effects of CS are more apparent when the exposure occurs in the developing lung rather than the mature adult lung.

The purpose of this study was to examine the effect of passive smoking on airway responsiveness to aerosol histamine, car- 
bachol, and citric acid in young lambs. The intent was to mimic the situation wherein parental smoking results in passive smoking by their children.

\section{METHODS}

Experimental protocol. Two groups of lambs were studied; 17 were exposed to CS and 13 served as age- and sex-matched controls. Starting at 1 month of age, CS lambs had a total of 25 daily (excluding weekends) exposures to CS generated as described in the following section. At each exposure eight nonfiltered, commercial cigarettes were used. Each cigarette had a tar content of $21 \mathrm{mg}$ and a nicotine content of $1.6 \mathrm{mg}$. Two days prior to lung function testing, lambs were anesthetized using intravenous pentobarbital and inhaled Metofane (methoxyflurane, Pittman Moore, Inc., Washington Crossing, NJ). Through a small, right-sided thoracotomy, a specially constructed Silastic envelope and catheter was placed in the pleural space for later measurement of pleural pressure. The envelope was made from Silastic sheeting (Dow Corning, Corning, NJ) and measured $3 \times$ $4 \mathrm{~cm}$; the Silastic catheter had an internal diameter of $1.5 \mathrm{~mm}$ and the portion within the envelope had multiple side holes.

At 2 months of age, both groups of lambs were studied. In each animal, baseline lung mechanics were measured. AR to aerosol histamine, carbachol, and citric acid was measured on 3 separate days in randomized order. For each lamb, AR was measured to one of the aerosol agents within $24 \mathrm{~h}$ of the final exposure to CS and to the other two agents at 3-7 days after the exposure. One to 2 days after the final measurement of $A R$, lambs were anesthetized and an open lung biopsy was performed through a thoracotomy at the 7 th intercostal space. For the biopsy, the lamb's lung was inflated to an airway opening pressure of $40 \mathrm{~cm} \mathrm{H}_{2} \mathrm{O}$ via the endotracheal tube, and a $4 \times 2 \mathrm{~cm}$ section of the caudal lobe was clamped and then removed. The inflated tissue was fixed in phosphate buffered formaldehyde ( $\mathrm{pH}$ 7.1), embedded in paraffin, sectioned ( $5 \mu \mathrm{m}$ thick cuts), and stained with hematoxylin and eosin.

Cigarette exposure. Smoke was generated by allowing a lighted cigarette to burn and also by drawing air through another lighted cigarette using a Bird Mark 2 Ventilator. The smoke from the two cigarettes was then blown into a 560 liter exposure chamber (which housed two lambs) using an 11 liter/min flow of fresh air. An exhaust fan vented the chamber. The Bird ventilator was used in the following manner to generate CS. The lighted cigarette was placed in a hollow metal holder which in turn was placed in a $500 \mathrm{ml}$ air-tight cylinder. (The hollow metal holder was the only outlet from the cylinder.) The Bird ventilator was set at a flow of 20 liters/min and a rate of 10 breaths per minute. By placing the output of the ventilator into the chamber with the lighted cigarette, a pressure of ${ }^{+} 10 \mathrm{~cm} \mathrm{H}_{2} \mathrm{O}$ was generated. This caused air to be forced through the cigarette thus generating the smoke. For each exposure, six cigarettes were smoked at 15min intervals using the ventilator and two cigarettes were allowed to burn. This total cigarette consumption of eight cigarettes per day took $1 \frac{1}{2} \mathrm{~h}$. The lambs were then returned to their mother where they had free access to food, water, and milk.

The number of cigarettes (8) was chosen after performing a pilot study to determine the number of cigarettes which caused an elevation in $\mathrm{COHb}$ level but no hypoxemia. Two days prior to study, sheep were anesthetized and a Silastic catheter placed in the thoracic aorta via the carotid artery. Three sheep were used in this pilot study. Arterial blood was drawn at baseline and immediately after exposure to the smoke from one, six, eight, ten, and 20 cigarettes. The blood was kept in heparinized syringes on ice and later analyzed for $\mathrm{PaO}_{2}$ and $\mathrm{COHb}$ using a Corning Blood Gas System (model 165/2, Medford, MA) and an Instrumentation Laboratory $\mathrm{COHb}$ analyzer (model 282, Lexington, MA). $\mathrm{COHb}$ started at a mean baseline of $6.6 \%$ for the three sheep and rose to $7.6 \%$ after one cigarette, $23.6 \%$ after six, $28.1 \%$ after eight, $20.7 \%$ after 10 , and $30.2 \%$ after 20 cigarettes. Mean
$\mathrm{PaO}_{2}$ was 91 (baseline), 82 (one cigarette), 90 (six cigarettes), 112 (eight cigarettes), and 73 (10 cigarettes). From these data, it was determined that eight cigarettes resulted, on the average, in a 4fold increase in $\mathrm{COHb}$ but no decrease in $\mathrm{PaO}_{2}$. A further increase to 10 cigarettes resulted in a decrease in $\mathrm{PaO}_{2}$ by almost $20 \mathrm{~mm}$ $\mathrm{Hg}$.

Measurements of lung mechanics. For each study, lambs were intubated nasally with a cuffed endotracheal tube using an Olympus BF 3C4 flexible pediatric fiberoptic bronchoscope. Awake lambs were studied while standing in a 254-liter whole-body, pressure-compensated, integrated-flow plethysmograph constructed from $1 \mathrm{~cm}$ plexiglass. A loosely fitting cloth sling was positioned under the sheep to prevent the animal from lying down during the experiment. The nasotracheal tube was connected to an external valve by flexible noncollapsible tubing. This external valve was used to obstruct the airway at end expiration during determination of FRC. A constant bias flow was used to reduce the effective dead space of the tubing.

$\mathrm{V}_{\mathrm{T}}$ was measured by pressure compensating the integrated signal from the plethysmographic pressure transducer. $\dot{V}$ was obtained by electronically differentiating the volume signal. $\mathrm{P}_{\mathrm{a}}$ was measured by a multiple side-holed catheter extending 1 $2 \mathrm{~cm}$ beyond the distal end of the nasotracheal tube. $P_{p l}$ was measured directly from the Silastic catheter and envelope in the pleural space. $P_{t p}$ was the pressure difference between $P_{p 1}$ and $\mathrm{P}_{\mathrm{ao}}$. All pressure signals were measured using Validyne differential pressure transducers and Validyne CD19 demodulators. The signals from the catheters and pleural envelopes were tuned to eliminate phasic distortion to $6 \mathrm{~Hz}$.

Simultaneous $\mathrm{V} / \mathrm{V}_{\mathrm{T}}$ and $\mathrm{P}_{\mathrm{tp}} / \mathrm{V}_{\mathrm{T}}$ curves were recorded on a Tektronix 5113 dual-beam storage oscilloscope and photographed for the calculation of Cdyn and $R_{L}$. Cdyn was calculated by dividing $V_{T}$ by $P_{t p}$ at points of zero flow and was expressed in liter/cm $\mathrm{H}_{2} \mathrm{O}$ at BTPS. $\mathrm{R}_{\mathrm{L}}$ was calculated by dividing $\mathrm{P}_{\mathrm{tp}}$ by $\stackrel{\circ}{ }$ at mid- $\mathrm{V}_{\mathrm{T}}$ and was expressed as $\mathrm{cm} \mathrm{H}_{2} \mathrm{O} \cdot \operatorname{liter}^{-1} \cdot \mathrm{s}$ at BTPS. FRC was measured using the Boyle's Law Method of Dubois et al. (14). RR was measured from the $\mathrm{P}_{\mathrm{tp}}$ tracing. $\mathrm{S}_{\mathrm{GL}}$ was calculated by dividing the reciprocal of $R_{L}$ by FRC. $S_{C d y n}$ was calculated by dividing Cdyn by FRC.

Cdyn, $R_{L}, F R C, S_{G L}, S_{C d y n}, R R$, and weight were measured at 2 months of age in CS and control lambs using the mean of the baseline values obtained on the 3 days when airway responsiveness was measured.

$A R$. AR to aerosolized histamine, carbachol, and citric acid was measured in CS lambs at the end of the smoke exposure and in control lambs at an equivalent age. Citric acid (Fisher Scientific Co., Springfield, NJ), carbamyl choline chloride (carbachol, Sigma Chemical Co., St. Louis, MO), and histamine disphosphate (Sigma Chemical Co.) were dissolved in sterile normal saline. Histamine solutions in concentrations of $0.1,0.3,1,3$, 10 , and $30 \mathrm{mg} / \mathrm{ml}$ of free histamine base were used. Citric acid in concentrations of $0.1,1,10$, and $100 \mathrm{mg} / \mathrm{ml}$ and carbachol in concentrations of $0.1,0.3,1,3$, and $10 \mathrm{mg} / \mathrm{ml}$ were used. Aerosols were generated using a Collison nebulizer driven by $100 \%$ oxygen at 50 psi. This nebulizer generates particles with a mass median diameter between 2 and $4 \mu(15)$.

$\mathrm{AR}$ to the aerosolized drug was quantitated in the following manner. Measurements of Cdyn, $\mathrm{R}_{\mathrm{L}}$, and FRC were made at 10min intervals until a stable baseline was reached (usually 30 to $60 \mathrm{~min}$ ). A stable baseline was defined according to previously established quantitation of the normal variability for repeat measurements in lambs. Then, five breaths of aerosolized normal saline to a $\mathrm{P}_{\mathrm{a} o}$ of $20 \mathrm{~cm} \mathrm{H}_{2} \mathrm{O}$ were given as a control and measurements of lung mechanics were made. At 10-min intervals, five breaths of increasing concentration of the drug was given until a significant change in Cdyn, $\mathrm{R}_{\mathrm{L}}$, or FRC occurred. The level of change required to be significant was determined previously by quantitating the degree of variability normally seen in repeat measurements in young lambs. In other words, the SD for repeat measurements of Cdyn, $R_{L}$, and FRC was calculated 
in a group of lambs and was a quantitation of normal variability. A change in a measurement that was greater than two times the SD was considered a significant change as opposed to a change of less than 2 SD which was considered as the noise of the measurement. This variability was the same as found in adult sheep for Cdyn and $R_{L}(16)$. However, young lambs had greater repeat test variability for FRC. Thus, the effective dose of the drug that caused a $35 \%$ reduction in Cdyn ( $\left.\mathrm{ED}_{65} \mathrm{Cdyn}\right)$, a doubling of $R_{L}\left(E D_{200} R_{L}\right)$, or a $50 \%$ change in FRC $\left(E D_{150} F R C\right)$ was calculated by linear interpolation.

Data analysis. Measurements of lung mechanics were compared between the smoking and nonsmoking lambs using an unpaired $t$ test. Fishers exact test was used to compare airway responsiveness between the two groups of lambs. A $p$ value of $<$ 0.05 was considered statistically significant. Data are expressed as mean $\pm 1 \mathrm{SD}$.

\section{RESULTS}

Lung biopsies were performed in four CS and three control lambs. In all four $\mathrm{CS}$ animals there was mild to moderate mononuclear infiltrate in the interstium. Alveolar walls were thickened with this cellular infiltrate but there was no exudate in the alveolar airspace (Fig. 1). None of the control animals had interstitial infiltrate (Fig. 2). All cross-sectional cuts of airways with intact epithelium were assessed for exudate, epithelial changes, and cellular infiltrate. An average of 16 airways were assessed per lamb (range 12-25). Two of the four CS lambs had peribronchial mononuclear infiltrate affecting approximately $25 \%$ of the airways found on the section (Fig. 3). None of the total of 55 airways assessed in control lambs had peribronchial inflammation. Cellular exudate were seen in the lumen of 13 , 20,33 , and $39 \%$ of the cross-sectional airways in the four CS lambs, respectively (Fig. 1). All four of these CS lambs had at least one airway with many cells $(>25)$ filling the airway lumen In contrast, cellular exudate was less evident (but still present) in the control lambs. Cells were seen in 12, 15, and $16 \%$ of the airways of the three control lambs. The number of cells per airway was usually one to three with none of the control lambs having airways with more than 15 cells. The epithelial cells were normal in both CS and control lambs.

Mean weight for the $17 \mathrm{CS}$ lambs was $16.5 \pm 4.7 \mathrm{~kg}(1 \mathrm{SD})$ at the time of study. In these CS animals, mean Cdyn was $0.024 \pm$ 0.009 liter $/ \mathrm{cm} \mathrm{H}_{2} \mathrm{O}, \mathrm{R}_{\mathrm{L}}$ was $2.56 \pm 1.32 \mathrm{~cm} \mathrm{H}_{2} \mathrm{O} \cdot$ liter $^{-1} \cdot \mathrm{s}$, and FRC was $0.725 \pm 0.234$ liter (Fig. 4). Mean weight of the 13 control lambs was $17.2 \pm 4.8 \mathrm{~kg}$, Cdyn was $0.030 \pm 0.012$ liter/ $\mathrm{cm} \mathrm{H}_{2} \mathrm{O}, \mathrm{R}_{\mathrm{L}}$ was $2.48 \pm 1.21 \mathrm{~cm} \mathrm{H}_{2} \mathrm{O} \cdot$ liter $^{-1} \cdot \mathrm{s}$, and $\mathrm{FRC}$ was $0.768 \pm 0.270$ liter at the equivalent age. There was no significant difference between the CS and control lambs using any of these measurements. Similarly, $\mathrm{S}_{\mathrm{GL}}, \mathrm{S}_{\mathrm{Cdyn}}$, and $\mathrm{RR}$ were not significantly different between the two groups.

As shown previously (17), 2-month-old lambs are generally unresponsive to aerosol challenge. Eight percent of the controls responded to aerosol histamine, $17 \%$ to carbachol, and $25 \%$ to citric acid. This represented six positive dose response curves; in 4/6 $R_{L}$ changed only, 1/6 Cdyn changed only, $1 / 6$ both $R_{L}$ and Cdyn changed, and in none did FRC change. CS did not significantly change airway responsiveness either within $24 \mathrm{~h}$ or at 37 days after the last CS exposure (Fig. 5).

\section{DISCUSSION}

We have shown that a short exposure ( $<1$ month) to CS in young lambs produces histologic changes in the lung without causing significant alterations in lung mechanics or airway reactivity. How do these data compare to other data in animals and humans? Adult beagles that smoked eight cigarettes per day for 6 months showed no significant change in lung morphology,

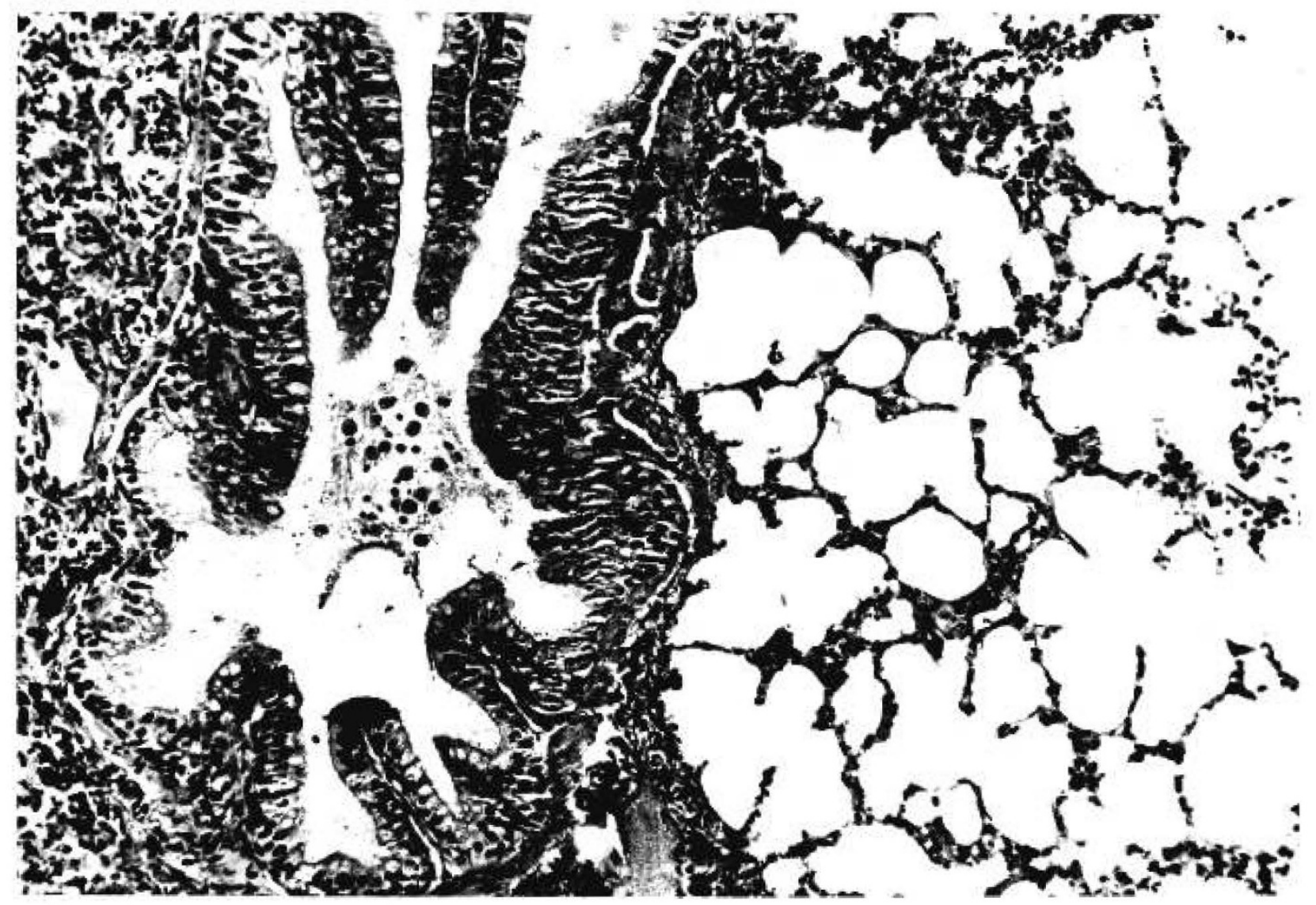

Fig. 1. Photomicrograph $(\times 160)$ of lung of CS exposure lamb showing airway with cellular exudate in lumen and mild mononuclear infiltrate of alveolar wall. 


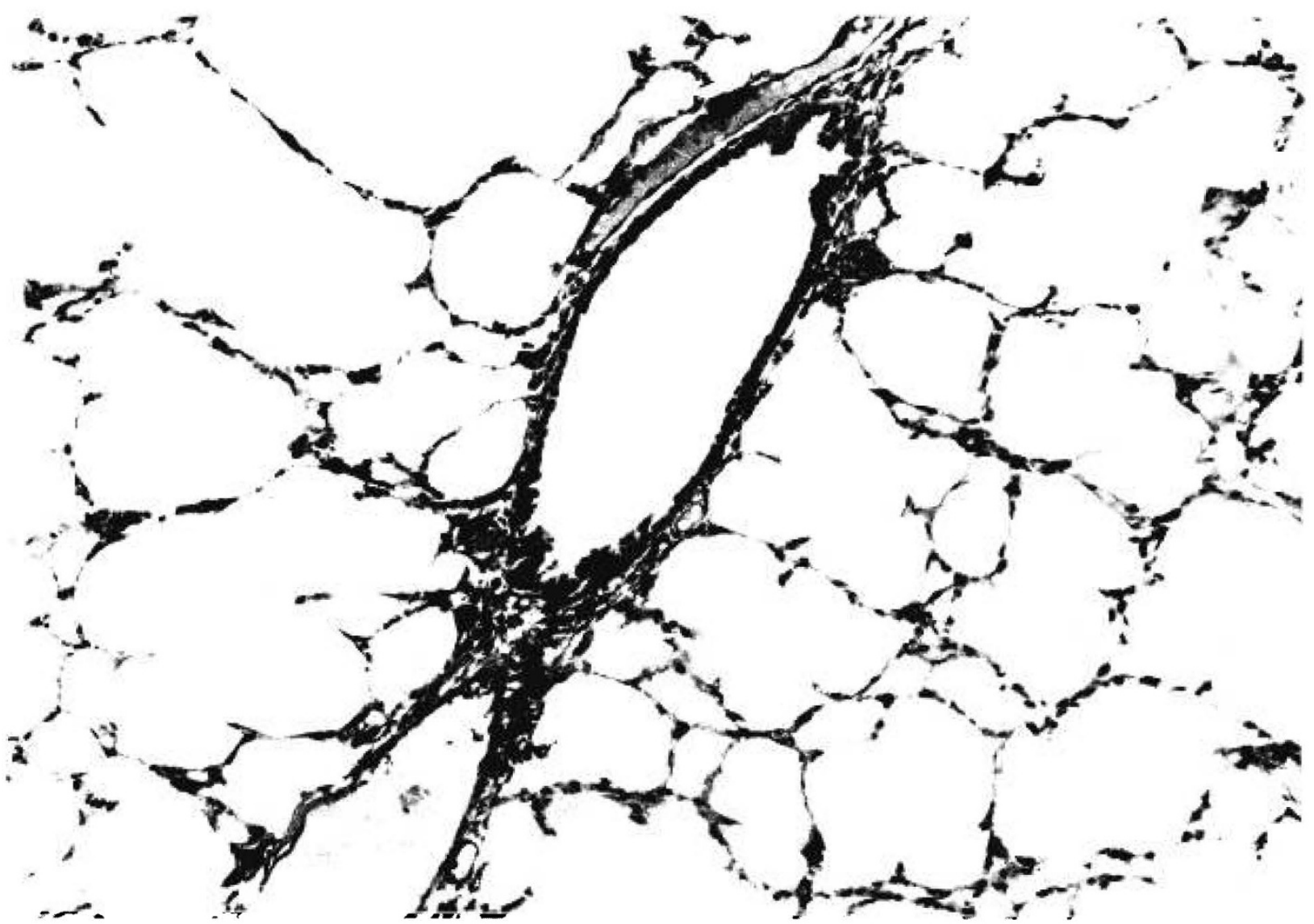

Fig. 2. Photomicrograph $(\times 160)$ of lung of control lamb. Normal small airway is seen. No interstitial inflammation is present.

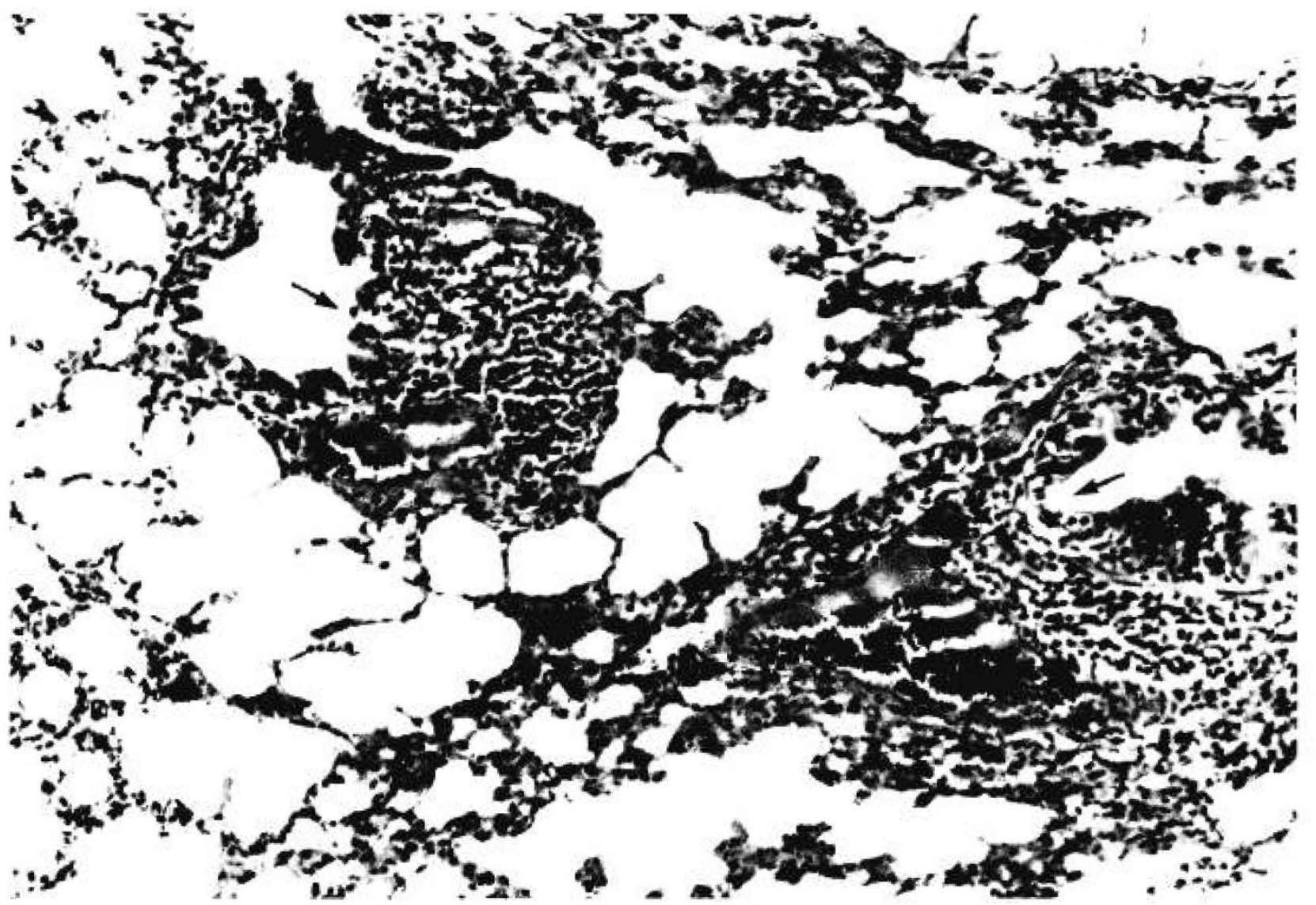

Fig. 3. Photomicrograph $(\times 160)$ of lung of CS exposure lamb showing two small airways with intense peribronchial mononuclear infiltrate (arrow). 

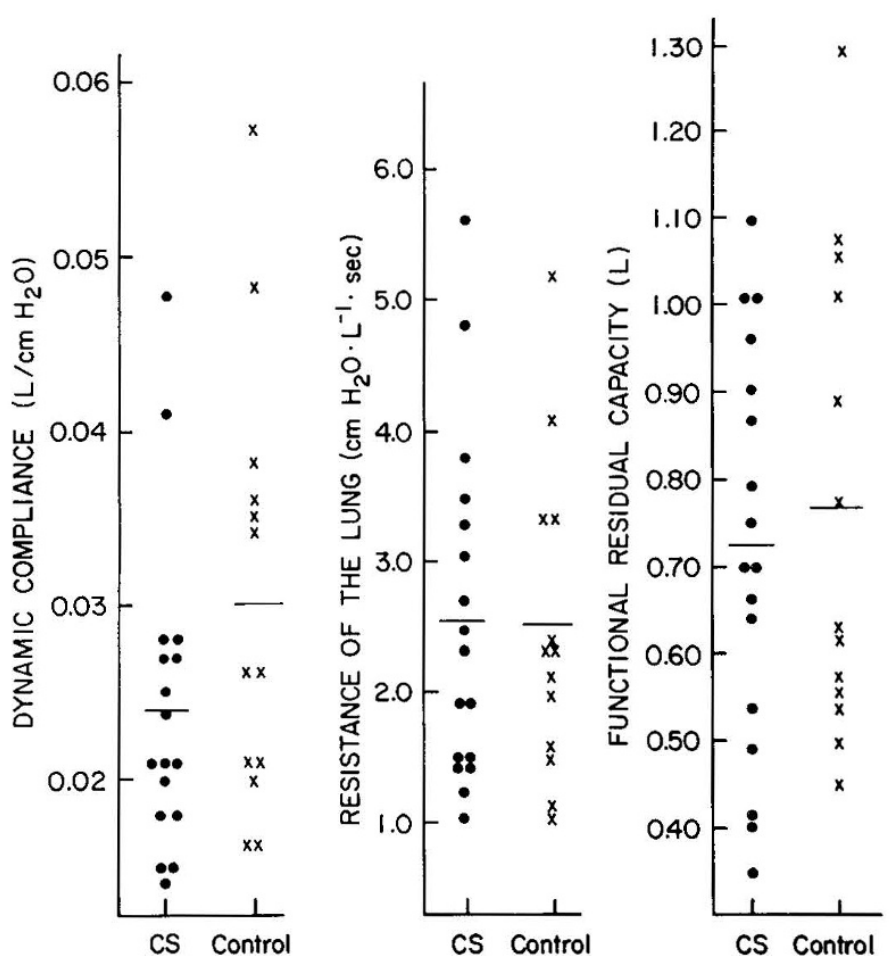

Fig. 4. Lung mechanics in $\mathrm{CS}$ exposure lambs after 25 daily exposures and in age- and sex-matched control lambs. The horizontal bar represents the mean for each group.

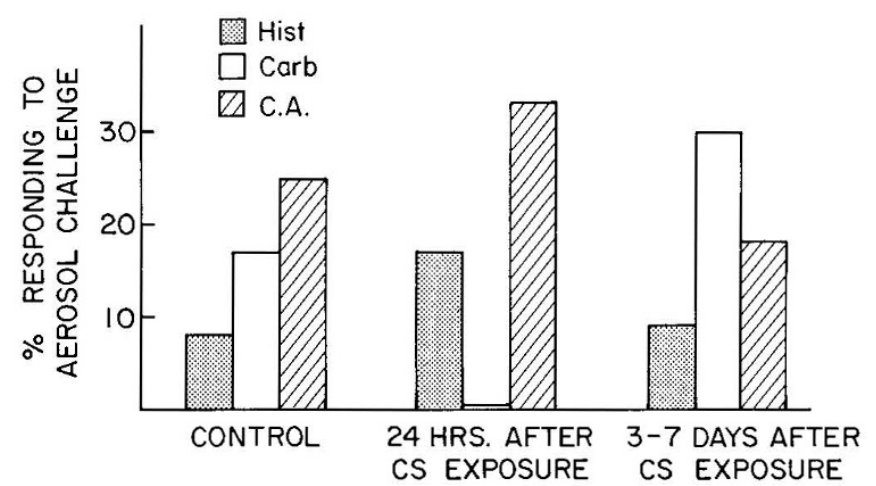

Fig. 5. Percent of lambs demonstrating a significant decrease in dynamic compliance with aerosol challenge to histamine, carbachol, or citric acid.

arterial blood gases, FRC, respiratory resistance, static compliance, or mucociliary clearance (18). However, after $1 \mathrm{yr}$, small changes in FRC and resistance were seen as well as more clearcut changes in lung morphology which included tracheal epithelial cell hyperplasia, increased goblet cells, and infiltration of peribronchiolar tissue by mononuclear cells and macrophages. Similarly, spouses of smokers required at least $15 \mathrm{yr}$ of daily exposure before a significant decrease in pulmonary function as measured by spirometry could be detected (7). In contrast, extensive morphologic changes, particularly at the level of the larynx, are seen in adult rats after a 12-wk exposure to CS (19). As little as 100 puffs of cigarette smoke causes significant polymorphonuclear cell infiltration into the airways of adult guinea pigs (20). Thus, not only is the length of exposure to CS important, but also the species and the indices of pulmonary function that are measured. Comparing young lambs to these other species, it appears that morphologic changes appear after a relatively short exposure time.

Another important factor producing a disruption in lung func- tion after exposure to CS may be the age of the subject. In the studies mentioned above, only adult animals and humans were examined. There is scant information on the effect of CS in the growing lung but epidemiologic data would suggest that the age at which exposure occurs is important (21). Granted the limitation of data obtained by questionnaire, the information of Colley et al. (2) implies that the effect of passive smoking is best seen in the 1st yr of life as evidenced by the increased incidence of bronchitis and pneumonia. Between 1 and $5 \mathrm{yr}$, a harmful effect from passive smoking could no longer be documented. Certainly studies in young children imply that even minor lung injury from a variety of causes occurring during infancy can years later significantly affect lung function (22).

Thus, it is not unreasonable to expect a short CS exposure to affect the lung in a young lamb when a longer exposure would produce little effect in adults. Histologic changes were seen following this short 1 month CS exposure in the young lamb whereas histologic changes are not seen until $1 \mathrm{yr}$ of exposure in adult beagles and 3 months in adult rats. However, no changes in lung mechanics were found. From Figure 4, the differences between CS exposure and control animals is singularly unimpressive for both $\mathrm{R}_{\mathrm{L}}$ and FRC. However, the $p$ value for comparing CS to control lambs using dynamic compliance is 0.13 . With the number of lambs studied, only a $26 \%$ or greater reduction in Cdyn could have been detected assuming a standard $\beta$ of 0.9 and a $p$ level of $<0.05$. With more lambs, or a longer exposure time, the magnitude of the type II error could have been reduced. An alternative explanation as to the lack of effect on lung mechanics is that Cdyn was measured too soon after CS exposure. Using young rats exposed to parainfluenza virus, Castleman (23) has shown a very interesting disruption of the normal morphologic developmental changes in the lung months after the acute infection. Thus, before it can be concluded that passive smoking does not affect lung mechanics in lambs, further variations on the experimental design may be necessary.

Asymptomatic adult smokers with normal pulmonary function by conventional measurements may have increased airway responsiveness to aerosol histamine and carbachol (9-12). However, this is not a universal phenomenon as some authors have been unable to document increased airway reactivity in smokers (24). We could find no increase in airway reactivity to carbachol, histamine, or citric acid with passive smoking. This failure to alter airway reactivity occurred despite histologic evidence of inflammation involving both the airways and the interstitium. The inflammatory response appears to be an important factor in the expression of airway reactivity. For example, white celldepleted sheep are significantly less responsive to aerosol histamine than sheep with a normal white cell count (25). Also, infusion of Escherichia coli endotoxin in adult sheep produces pulmonary edema, sequestration of white cells in the lung, and an acute increase in airway responsiveness to aerosol hitamine (26). Thus, the failure to increase airway reactivity in the face of active inflammation in the lung in our lambs suggests that CS is not associated with increased airway reactivity. Further evidence questioning the link between airway reactivity and smoking comes from Roehrs et al. (13), who actually showed a decreased reactivity to aerosol methacholine in adult baboons who smoked two packs per day for $3 \mathrm{yr}$.

\section{REFERENCES}

1. Editorial 1978 Breathing other people's smoke. Br Med J 6135:453-454

2. Colley JRT, Holland WW, Corkhill RT 1974 Influence of passive smoking and parental phlegm on pneumonia and bronchitis in early childhood. Lancet 2:1031-1034

3. Fergusson DM, Horwood LJ, Shannon FT 1980 Parental smoking and respiratory illness in infancy. Arch Dis Child 55:358-361

4. Fergusson DM, Horwood LJ, Shannon FT, Taylor B 1981 Parental smoking and lower respiratory illness in the first three years of life. $\mathbf{J}$ Epidemiol Community Health 35:180-184

5. Weiss ST, Tager IB, Speizer FE, Rosner B 1980 Persistent wheeze. Its relation to respiratory illness, cigarette smoking, and level of pulmonary function in a population sample of children. Am Rev Respir Dis 122:697-707 
6. Tager IB, Weiss ST, Muñoz A, Rosner B, Speizer FE 1983 Longitudinal study of the effects of maternal smoking on pulmonary function in children. $\mathrm{N}$ Engl J Med 309:699-703

7. Kauffmann F, Tessier J-F, Oriol P 1983 Adult passive smoking in the home environment: a risk factor for chronic airflow limitation. Am J Epidemiol 117:269-280

8. Higenbottam T, Feyeraband C, Clark TJH 1980 Cigarette smoke inhalation and the acute airway response. Thorax 35:246-254

9. Buczko GB, Day A, Vanderdoelen JL, Boucher R, Zamel N 1984 Effects of cigarette smoking and short-term smoking cessation on airway responsiveness to inhaled methacholine. Am Rev Respir Dis 129:12-14

10. Gerrard JW, Cockcrocft DW, Mink JT, Cotton DJ, Poonawala R, Dosman JA 1980 Increased nonspecific bronchial reactivity in cigarette smokers with normal lung function. Am Rev Respir Dis 122:577-581

11. Kabiraj MU, Simonsson BG, Groth S, Björklund A, Bülow K, Lindell S-E 1982 Bronchial reactivity, smoking and alpha $a_{1}$-antitrypsin. Am Rev Respir Dis 126:864-869

12. Malo JL, Filiatrault S, Martin RR 1982 Bronchial responsiveness to inhaled methacholine in young asymptomatic smokers. J Appl Physiol 52:14641470

13. Roehrs JD, Rogers WR, Johanson WG Jr 1981 Bronchial reactivity to inhaled methacholine in cigarette-smoking baboons. J Appl Physiol 50:754-760

14. Dubois AB, Botelho SY, Bedell GN, Marshall R, Comroe JH 1956 A rapid plethysmographic method measuring thoracic gas volume: a comparison with a nitrogen washout method for measuring functional residual capacity in normal subjects. J Clin Invest 35:322-326

15. Snapper JR, Drazen JM, Loring SH, Schneider W, Ingram RH Jr 1978 Distribution of pulmonary responsiveness to aerosol histamine in dogs. J Appl Physiol 44:738-742

16. Hutchison AA, Brigham KL, Snapper JR 1982 Effect of histamine on lung mechanics in sheep: comparison of aerosol and parenteral administration. Am Rev Respir Dis 126:1025-1029

17. Sauder RA, McNicol KJ, Hutchison AA 1985 Effect of age on lung mechanics and airway reactivity (AR) in lambs. Am Rev Respir Dis 131:A245

18. Park SS, Kikkawa Y, Goldring IP, Daly MM, Zelefsky M, Shim C, Spierer M, Morita T 1977 An animal model of cigarette smoke in beagle dogs. Correlative evaluation of effects on pulmonary function, defense and morphology. Am Rev Respir Dis 115:971-979

19. Coggins CRE, Fouillet XLM, Lam R, Morgan KT 1980 Cigarette smoke induced pathology of the rat respiratory tract: a comparison of the effects of the particulate and vapour phases. Toxicology 16:83-101

20. Hulbert WC, Walker DC, Jackson A, Hogg JC 1981 Airway permeability to horseradish peroxidase in guinea pigs: the repair phase after injury by cigarette smoke. Am Rev Respir Dis 123:320-326

21. Weiss ST, Tager IB, Schenker M, Speizer FE 1983 The health effects of involuntry smoking. Am Rev Respir Dis 128:933-942

22. Kattan M, Keen TG, Lapiere J-G, Levison H, Bryan C, Reilly BJ 1977 Pulmonary function abnormalities in symptom-free children after bronchiolitis. Pediatrics 59:683-688

23. Castieman WL 1985 Alterations in postnatal lung growth induced in young rats by parainfluenza infection. Am Rev Respir Dis 131:A243

24. Kennedy SM, Elwood RK, Wiggs BJR, Pare PD, Hogg JC 1984 Increased airway mucosal permeability of smokers. Am Rev Respir Dis 129:143-148

25. Hinson JM Jr, Hutchison AA, Brigham KL, Meyrick BO, Snapper HR 1984 Effects of granulocyte depletion on pulmonary responsiveness to aerosol histamine. J Appl Physiol 56:411-417

26. Hutchison AA, Hinson JM Jr, Brigham KL, Snapper JR 1983 Effect of endotoxin on airway responsiveness to aerosol histamine in sheep. $J$ Appl Physiol 54:1463-1468 